\title{
Impact of surgeon subspecialty training on surgical outcomes in open globe injuries
}

\author{
This article was published in the following Dove Press journal: \\ Clinical Ophthalmology \\ 28 September 2015 \\ Number of times this article has been viewed
}

\author{
lan C Han' \\ Sidharth Puri' \\ Jiangxia Wang ${ }^{2}$ \\ Shameema Sikder' \\ 'Wilmer Eye Institute, Johns Hopkins \\ University School of Medicine, \\ ${ }^{2}$ Bloomberg School of Public Health, \\ Johns Hopkins University, Baltimore, \\ MD, USA
}

Purpose: The purpose of this study was to evaluate whether subspecialty training of the initial treating surgeon affects visual acuity and surgical outcomes in patients with open globe injuries. Design: This study is a single-institution, retrospective case series.

Methods: The charts of adult patients with open globe injuries requiring surgical repair at the Wilmer Eye Institute between July 1, 2007 and July 1, 2012 were retrospectively reviewed. Clinical findings at presentation were recorded, and details of initial repair and follow-up surgeries were analyzed. Differences in visual acuity and surgical outcomes were compared based on subspecialty training of the initial surgeon.

Results: The charts of 282 adult patients were analyzed, and 193 eyes had at least 6 months of follow-up for analysis. Eighty-six eyes (44.6\%) required follow-up surgery within the first year, and 39 eyes $(20.2 \%)$ were enucleated. Eyes initially treated by a vitreoretinal (VR) surgeon were 2.3 times $(P=0.003)$ more likely to improve by one Ocular Trauma Score (OTS) visual acuity category and 1.9 times $(P=0.027)$ more likely to have at least one more follow-up surgery at 6 months compared to eyes treated by non-VR surgeons. Patients with more anterior injuries treated by a VR surgeon were more likely to improve by one OTS visual acuity category compared to those treated by non-VR surgeons ( $P=0.004$ and 0.016 for Zones I and II, respectively). There was no difference in visual acuity outcomes for eyes with posterior injuries $(P=0.515$ for Zone III).

Conclusion: Eyes initially treated by a VR surgeon are more likely to improve by one OTS visual acuity category than those initially treated by a non-VR surgeon. However, patients initially treated by a VR surgeon also undergo more follow-up surgical rehabilitation, and improvement in visual acuity is more likely for anterior (Zone I and II injuries) than posterior (Zone III) injuries.

Keywords: surgical repair, follow-up surgery, visual acuity, Ocular Trauma Score, vitreoretinal surgeon, afferent pupillary defect

\section{Background}

Open globe injuries are a major cause of vision loss worldwide, ${ }^{1-4}$ with an estimated 200,000 open globe injuries occurring worldwide each year. ${ }^{5}$ Because of the heterogeneity of traumatic injuries, standardized terminology to describe traumatic eye injuries has been developed, ${ }^{6}$ and these terms were summarized as the Birmingham Eye Trauma Terminology. ${ }^{7}$ Multiple classification schemes have also been developed, including by the Ocular Trauma Classification Group, who classified traumatic globe injuries based on four variables that had predictive value in estimating final visual outcomes: mechanism of injury, grade of injury as defined by presenting visual acuity, presence or absence of an afferent pupillary defect (APD), and zone of injury based on its most posterior extent. . $^{8}$

Several scoring systems have been devised to isolate factors at presentation predictive of poor prognosis. One widely used scoring system is the Ocular Trauma Score
Correspondence: Shameema Sikder Wilmer Eye Institute, Johns Hopkins University School of Medicine, 7315

Wisconsin Avenue, West Tower, Suite 6I0, Bethesda, MD 208I4, USA

$\mathrm{Tel}+\mathrm{I} 240482$ I I00

Email ssikderl@jhmi.edu 
(OTS), which was developed following analysis of $>2,500$ open globe injuries and identified presenting visual acuity, presence of APD, mechanism of injury, retinal detachment, or endophthalmitis as key variables. ${ }^{10}$ The OTS assigns numeric values to each of the variables mentioned earlier to determine a scoring category that is predictive of final visual acuity. Subsequent studies have demonstrated the OTS' validity in predicting final visual acuity, ${ }^{11-14}$ though the scoring system may be less reliable in pediatric populations. ${ }^{15}$

While numerous published reports have examined the prognostic factors for traumatic globe injuries, fewer studies have evaluated the types and number of surgeries required for treatment of traumatic globe injuries. Andreoli and Andreoli recently described long-term surgical rehabilitation of open globe injuries and found that patients on average required 1.7 surgeries and that more severe OTS predicted the need for follow-up surgery. ${ }^{16}$

To our knowledge, no studies have investigated whether outcomes differ based on the subspecialty training of the surgeon at time of the initial open globe repair. For example, a patient with a Zone III injury (defined by the Ocular Trauma Classification Group as extending $>5 \mathrm{~mm}$ posterior to the limbus) may be referred to a vitreoretinal (VR) surgeon for primary repair, but data are limited as to whether visual acuity outcomes are better with a trained VR surgeon compared to a non-retina specialist, or whether having a subspecialist perform the initial repair will decrease the need for further surgeries after the initial repair.

In this study, we describe the characteristics of open globe injuries presenting to an urban, tertiary trauma center in comparison to prior studies from our institution, and evaluate outcomes based on previously studied prognostic indicators including OTS and zone of injury. We further evaluate whether outcomes such as visual acuity, number and type of post-repair procedures, and need for enucleation differ based on the subspecialty training of the surgeon performing initial repair.

\section{Methods}

This is a single-center, retrospective chart review of consecutive adult patients ( $\geq 18$ years old) who presented to the Wilmer Eye Institute, The Johns Hopkins Hospital, from July 1, 2007 to July 1, 2012 with open globe injuries as defined as a full-thickness wound of the eye wall. Institutional review board approval was obtained from the Johns Hopkins Medicine Institutional Review Board.

Patients at the Wilmer Eye Institute at Johns Hopkins Hospital are treated for open globe injuries with a standardized protocol including complete history, ocular examination, and consent for surgical repair. All patients are evaluated by ophthalmology house staff and examined by a fellowshiptrained attending ophthalmologist. A non-contrast computed tomography scan with thin cuts through the orbits is obtained unless contraindicated. Initial treatment includes a single dose of intravenous antibiotics (usually moxifloxacin, a fourthgeneration fluoroquinolone) and an updated tetanus shot. Surgical repair is performed as soon as possible, generally within 24 hours unless prohibited by active medical issues. The initial globe repair is performed by the attending on call, in general regardless of zone of injury, unless the initial injury necessitates a subspecialist (eg, metallic intraocular foreign body $[\mathrm{IOFB}]$ in the posterior segment requiring a VR specialist at time of initial repair). Intravitreal antibiotics (typically vancomycin and ceftazidime) are administered intraoperatively. Patients are typically discharged to home if medically stable or admitted to address outstanding medical issues. We do not routinely administer oral or intravenous antibiotics postoperatively for isolated ocular injuries.

Patient charts were reviewed to determine patient demographics including age and sex as well as previous ocular history. Data from examination findings at presentation included mechanism of injury, visual acuity, presence of a relative APD, descriptive extent of injury, hyphema, uveal prolapse, vitreous hemorrhage, retinal detachment, IOFB, orbital fracture, or adnexal laceration. Data recorded at follow-up visits included visual acuity, intraocular pressure, and details regarding any follow-up procedures. For each patient, OTSs were calculated when possible based on available data, ${ }^{10}$ and each injury was also classified by mechanism, grade, and zone of injury based on the Ocular Trauma Classification Group categories. ${ }^{8}$

Data collected regarding initial surgical repair included the need for additional procedures, including anterior chamber (AC) washout, anterior vitrectomy, extraocular muscle involvement (including need to disinsert and reinsert muscles to determine extent of injury), lensectomy, pars plana vitrectomy (PPV), scleral buckle (SB), IOFB removal, and enucleation. For follow-up surgeries, defined as procedures performed at a separate visit following the initial repair of the globe injury, the surgical data recorded included any of the procedures listed earlier, as well as need for wound revision, intraocular lens placement, penetrating keratoplasty, glaucoma filter or tube placement, membrane peel, use of intraocular gas or oil, retinectomy, or choroidal drainage. The subspecialty training of the attending surgeon was noted for both the initial repair and any follow-up surgeries. For the 
purposes of primary enucleation, which were all performed by attendings with oculoplastic subspecialty training, the subspecialty training of the attending who either attempted initial repair or referred primarily for enucleation was noted.

Primary outcome measures included visual acuity at 6 months and 12 months post-repair, number of follow-up surgeries, and time until first follow-up surgery or enucleation. Eyes were excluded from specific analysis if measures being analyzed were not included or if follow-up data were unavailable for past 6 months. Visual acuity was categorized into five categories based on the OTS: 1) no light perception (NLP), 2) light perception or hand motion, 3) 1/200-19/200, 4) 20/200-20/50, and 5) $\geq 20 / 40$. Eyes that were enucleated were considered to be of NLP category for the purpose of analyzing visual acuity outcomes.

Statistical analysis was performed with a $P$-value of $<0.05$ considered statistically significant. Unpaired $t$-tests were used to compare means between groups. Multiple logistic regression analysis was performed using StataCorp LP 2013 (StataCorp LP, College Station, TX, USA).

\section{Results}

There were a total of 283 open globe injuries from 282 adult patients seen from July 1, 2007 to July 1, 2012. Only one patient suffered bilateral open globe injuries in this time period. The mean age of patients was 46.6 years. Seventyfive percent (212/282) of the patients were male, and $25 \%$ $(71 / 282)$ were female. Two hundred and fifty-two patients (89\%) were not documented as wearing glasses, goggles, or any other form of eye protection at time of injury. Out of the 282 patients, one patient had insufficient clinical information to characterize the type of injury or zone of injury per chart review. The majority of injuries were considered ruptures (130/282; 46\%), most commonly extending into Zone II $(121 / 282 ; 43 \%)$ per the Open Globe Injury Classification scheme (Table 1). ${ }^{8}$

Out of the 283 total injuries reviewed, 193 eyes from 192 patients reached 6 months of follow-up for inclusion for further analysis. The demographics of this patient population were similar to the overall patient population in our study, with 143 patients $(75 \%)$ being male and with a mean age of 46 years. The distribution of type of injury was also similar, with ruptures (91/192; 47\%) involving Zone II (75/192; 39\%) being most common (Table 1).

The most common additional procedures performed in addition to globe closure at the time of initial globe repair are shown in Table 2 . Approximately $20 \%$ of patients required $\mathrm{AC}$ washout or manipulation of an extraocular muscle.
Table I Distribution of injuries by type and zone according to the Open Globe Injury Classification scheme

\begin{tabular}{|c|c|c|c|c|}
\hline & \multicolumn{2}{|c|}{ All patients } & \multicolumn{2}{|c|}{$\begin{array}{l}\text { Patients with } \\
6 \text { months of follow-up }\end{array}$} \\
\hline & $\begin{array}{l}\text { Number } \\
\text { of eyes }\end{array}$ & $\begin{array}{l}\% \text { of } \\
\text { eyes }\end{array}$ & $\begin{array}{l}\text { Number } \\
\text { of eyes }\end{array}$ & $\begin{array}{l}\% \text { of } \\
\text { eyes }\end{array}$ \\
\hline \multicolumn{5}{|l|}{ Injury type } \\
\hline Penetrating & 118 & 41.7 & 75 & 39.1 \\
\hline Rupture & 130 & 45.9 & 91 & 47.4 \\
\hline IOFB & 28 & 9.9 & 20 & 10.4 \\
\hline Perforating & 6 & 2.1 & 6 & 3.1 \\
\hline Total & 282 & 100 & 192 & 100 \\
\hline \multicolumn{5}{|c|}{ Injury zone } \\
\hline Zone I & 79 & 28.0 & 58 & 30.2 \\
\hline Zone II & 121 & 42.9 & 75 & 39.1 \\
\hline Zone III & 82 & 29.1 & 59 & 30.7 \\
\hline Total & 282 & 100 & 192 & 100 \\
\hline
\end{tabular}

Abbreviation: IOFB, intraocular foreign body.

When comparing rates of additional procedures performed between VR surgeons and non-VR surgeons, AC washout, $\mathrm{SBs}$, and PPV were noted to be different to a statistically significant degree.

A total of 86 out of 193 eyes (45\%) required follow-up surgery within the first year after initial injury, with average time until first follow-up surgery of 7.1 weeks. The most common follow-up procedures were PPV (70/193; 36\%), AC washout $(52 / 193 ; 27 \%)$, and lensectomy $(48 / 191 ; 25 \%)$. Thirty-nine out of the 193 eyes (20\%) were enucleated within 12 months of initial repair, with average time to enucleation of 3.2 weeks. Twelve eyes (7\%) underwent primary enucleation at time of initial examination and/or attempted repair (Table 3).

There were a total of 36 different surgeons who performed open globe repairs in this study: twenty-one VR, six cornea, three uveitis, five oculoplastic, and one glaucoma. One hundred and thirty-one out of the 193 eyes were repaired by a VR surgeon, and 62 repaired by other surgeons ( 28 eyes cornea, 24 uveitis, nine oculoplastic, one glaucoma). Patients treated by the 15 non-VR surgeons were compared against those treated by the 21 VR surgeons. There was no statistically significant difference in initial OTS raw score, OTS category, or zone of injury between these two subsets of patients (Table 4).

The rate and distribution of follow-up surgeries performed were similar regardless of the subspecialty training of the initial surgeon, with notable exceptions of AC washout $(P=0.02)$ and $\mathrm{SB}(P=0.03)$. There were more primary enucleations performed in the non-VR group $(P=0.01)$, though the rates of secondary enucleation were similar (Table 3 ).

At 6 months, approximately a quarter of eyes were NLP, and another quarter were $\geq 20 / 40$. Visual acuity outcomes 
Table 2 Number and percentage of patients receiving additional procedures at time of initial globe repair for all patients and stratified if performed by VR surgeon or non-VR surgeon

\begin{tabular}{|c|c|c|c|c|c|c|c|}
\hline \multirow[t]{2}{*}{ Procedure } & \multicolumn{2}{|l|}{ Overall } & \multicolumn{2}{|l|}{ VR } & \multicolumn{2}{|l|}{ Non-VR } & \multirow[t]{2}{*}{$P$-value } \\
\hline & $\begin{array}{l}\text { Number of } \\
\text { procedures }\end{array}$ & $\begin{array}{l}\% \text { of } \\
\text { patients }\end{array}$ & $\begin{array}{l}\text { Number of } \\
\text { procedures }\end{array}$ & $\begin{array}{l}\% \text { of } \\
\text { patients }\end{array}$ & $\begin{array}{l}\text { Number of } \\
\text { procedures }\end{array}$ & $\begin{array}{l}\% \text { of } \\
\text { patients }\end{array}$ & \\
\hline AC washout & 40 & 20.7 & 33 & 25.2 & 7 & 11.3 & 0.01 \\
\hline Anterior vitrectomy & 16 & 8.3 & II & 8.4 & 5 & 8.1 & 0.94 \\
\hline EOM isolated & 40 & 20.7 & 29 & 22.1 & II & 17.7 & 0.47 \\
\hline IOFB removal & 20 & 10.4 & 15 & 11.5 & 5 & 8.1 & 0.45 \\
\hline Lensectomy & 20 & 10.4 & 14 & 10.7 & 6 & 9.7 & 0.83 \\
\hline PPV & 8 & 4.1 & 8 & 6.1 & 0 & 0 & 0.004 \\
\hline SB & 12 & 6.2 & 12 & 9.2 & 0 & 0 & 0.0004 \\
\hline
\end{tabular}

Notes: Data in bold indicates statistical significance.

Abbreviations: VR, vitreoretinal; AC, anterior chamber; EOM, extraocular muscle; IOFB, intraocular foreign body; PPV, pars plana vitrectomy; SB, scleral buckle.

for all patients at 6 months and 12 months are shown in Table 5. Visual outcomes were compared for those initially treated by a VR surgeon and a non-VR surgeon. Eyes initially treated by a VR surgeon were 2.3 times more likely to improve by one OTS visual acuity category at 6 months $(P=0.003)$ compared to eyes treated by non-VR surgeons, and this difference remained statistically significant at 12 months $(P=0.019)$.

When controlling for initial zone of injury, patients with more anterior injuries treated by a VR surgeon were more likely to improve by one OTS visual acuity category compared to those treated by non-VR surgeons $(P=0.004$ and 0.016 for Zones I and II, respectively). There was no statistically significant difference in visual acuity outcomes for eyes with posterior injuries ( $P=0.52$ for Zone III). Data are shown in Table 6.

Eyes initially treated by VR surgeons were also 1.9 times more likely to have at least one more follow-up surgery at 6 months compared to non-VR surgeons $(P=0.027)$, and this difference was no longer statistically significant at 12 months ( $P=0.07$ ). When controlling for zone of injury, eyes with Zone II injuries received more surgical rehabilitation when initially treated by a VR surgeon versus non-VR surgeon $(P=0.048)$, while rates of follow-up surgery for Zone I and III patients were similar (Table 6). The average time to the first follow-up surgery for the VR group was 6.7 weeks compared to 7.6 weeks for the non-VR group, and this difference was not statistically significant $(P=0.52)$.

Table 3 Number and percentage of patients requiring follow-up surgeries for all patients and stratified by whether a VR surgeon or non-VR surgeon performed the initial globe repair

\begin{tabular}{|c|c|c|c|c|c|c|c|}
\hline \multirow[t]{2}{*}{ Procedure } & \multicolumn{2}{|l|}{ Overall } & \multicolumn{2}{|l|}{ VR } & \multicolumn{2}{|l|}{ Non-VR } & \multirow[t]{2}{*}{$\overline{P \text {-value }}$} \\
\hline & $\begin{array}{l}\text { Number of } \\
\text { procedures }\end{array}$ & $\begin{array}{l}\% \text { of } \\
\text { patients }\end{array}$ & $\begin{array}{l}\text { Number of } \\
\text { procedures }\end{array}$ & $\begin{array}{l}\% \text { of } \\
\text { patients }\end{array}$ & $\begin{array}{l}\text { Number of } \\
\text { procedures }\end{array}$ & $\begin{array}{l}\% \text { of } \\
\text { patients }\end{array}$ & \\
\hline Wound revision & 5 & 2.6 & 3 & 2.3 & 2 & 3.2 & 0.73 \\
\hline Anterior chamber washout & 51 & 26.6 & 41 & 30.2 & 10 & 16.1 & 0.02 \\
\hline Penetrating keratoplasty & 11 & 5.7 & 6 & 4.7 & 5 & 8.1 & 0.39 \\
\hline Anterior vitrectomy & 22 & 11.5 & 16 & 12.4 & 6 & 9.7 & 0.57 \\
\hline Tube/trabeculectomy & 2 & 1.0 & 2 & 1.6 & 0 & 0 & 0.16 \\
\hline Lensectomy & 48 & 25.0 & 35 & 27.1 & 13 & 21.0 & 0.35 \\
\hline IOL insertion & 19 & 9.9 & 14 & 10.9 & 5 & 8.1 & 0.53 \\
\hline PPV & 70 & 36.5 & 54 & 31.0 & 16 & 16.1 & 0.12 \\
\hline Gas & 19 & 9.9 & 15 & 10.9 & 4 & 6.5 & 0.24 \\
\hline Oil & 20 & 10.4 & 15 & 10.1 & 5 & 6.5 & 0.50 \\
\hline Cryo & 4 & 2.1 & 3 & 2.3 & I & 1.6 & 0.73 \\
\hline Laser & 47 & 24.5 & 35 & 18.6 & 12 & 11.3 & 0.41 \\
\hline Membrane peel & 23 & 12.0 & 18 & 10.1 & 5 & 6.5 & 0.31 \\
\hline Retinectomy & 10 & 5.2 & 9 & 6.2 & I & 1.6 & 0.07 \\
\hline Scleral buckle & 33 & 17.2 & 27 & 20.9 & 6 & 9.7 & 0.03 \\
\hline Drain choroidals & 4 & 2.1 & 2 & 1.6 & 2 & 3.2 & 0.51 \\
\hline Enucleation & 39 & 20.3 & 22 & 16.5 & 17 & 28.3 & 0.08 \\
\hline Primary & 12 & 6.3 & 3 & 2.3 & 9 & 15.0 & 0.01 \\
\hline Secondary & 27 & 14.1 & 19 & 14.3 & 8 & 13.3 & 0.86 \\
\hline
\end{tabular}

Notes: Data in bold indicates statistical significance.

Abbreviations: VR, vitreoretinal; IOL, intraocular lens; PPV, pars plana vitrectomy. 
Table 4 Mean OTS raw score, visual acuity category, and Open Globe Injury Classification zone of injury compared between patients initially treated by a VR surgeon or a non-VR surgeon

\begin{tabular}{llll}
\hline & VR & Non-VR & P-value \\
\hline Average OTS raw score & 61.1 & 56.3 & 0.18 \\
Average OTS category & 2.5 & 2.3 & 0.22 \\
Average zone of injury & 2.0 & 2.0 & 0.90 \\
\hline
\end{tabular}

Abbreviations: OTS, Ocular Trauma Score; VR, vitreoretinal.

\section{Discussion}

The data presented in this study represent our experience of 5-year period treating adult patients with traumatic open globe injuries at an urban, tertiary referral center. Numerous previous studies performed at our institution have characterized mechanisms of injuries, identified key prognostic factors, and described visual outcomes for patients with traumatic globe injuries. ${ }^{17-20}$ When compared to a similar series of 476 eyes from patients who presented to our institution from 1970 to $1981,{ }^{18}$ and 290 eyes from patients who presented from 1985 to $1993,{ }^{20}$ our patients actually had a lower rate of final visual acuity $\geq 20 / 40$ ( $21 \%$ in our series from 2007 to 2012 compared to $39 \%$ from 1970 to 1981 and $36 \%$ from 1985 to 1993). This may be reflection of demographics, as our patient population, which included only adults, tended to be older (mean age 46 years compared to 31 years for 1985-1993). In addition, injuries in our study tended to be more posterior (only $28 \%$ of eyes with isolated corneal injuries compared to $41 \%$ from 1985 to 1993). Furthermore, there was a much higher proportion of globe ruptures in our study (47\% compared to $30 \%$ from 1985 to 1993), which also predispose toward a poorer outcome per previous prognostic studies.

While many previous studies have focused on identifying factors important for prognosticating outcomes following open globe injuries, fewer studies have evaluated the surgical rehabilitation required for patients who suffer traumatic globe injuries. In our study, $45 \%$ of eyes (86/193) required follow-up surgeries within the first year. This rate is the same as that reported in a recent study by Andreoli and Andreoli. ${ }^{16}$ As in their study, lensectomy and PPV were the two most common follow-up procedures performed after initial globe repair.

Recognizing that nearly half of patients with traumatic globe injuries require follow-up surgeries, our study further addresses the issue of whether the subspecialty training of the surgeon performing the initial globe repair affects final visual outcomes or number of follow-up surgeries required. The data suggest that eyes initially treated by a VR surgeon were 2.3 times more likely to improve by one OTS visual acuity category by 6 months $(P=0.003)$ compared to eyes treated by non-VR surgeons, and this difference remained statistically significant at 12 months.

The differences in visual acuity outcomes in our study population may be explained by several different factors. For one, patients treated initially by a VR surgeon have more procedures performed at time of initial repair. These included retina-specific procedures such as PPV or SB, as might be expected, given the VR background of these surgeons. While a non-VR surgeon may opt simply to close the open globe at time of initial repair, surgeons with VR training may pursue additional steps in the initial surgery to secure the globe injury and start surgical rehabilitation. This may indicate not only that the subspecialty training of the attending surgeon influences outcome but also that VR-specific procedures conducted at the time of open globe injury may be important for improved patient outcome.

Even when a VR surgeon performs the initial globe closure, numerous factors may contribute to staging surgical rehabilitation, including the stability of the eye at time of primary closure for further surgery, the presence of adequate view for posterior segment surgery, and restoration of ocular anatomy more representative of normal once primary closure has been performed. In our study, despite undergoing more

Table 5 Visual acuity outcomes at 6 months and 12 months for all patients, and stratified if initially treated by a VR surgeon or a nonVR surgeon

\begin{tabular}{|c|c|c|c|c|c|c|c|c|c|c|c|c|}
\hline \multirow[t]{3}{*}{ Visual acuity } & \multicolumn{4}{|l|}{ Overall } & \multicolumn{4}{|l|}{ VR } & \multicolumn{4}{|l|}{ Non-VR } \\
\hline & \multicolumn{2}{|l|}{6 months } & \multicolumn{2}{|c|}{12 months } & \multicolumn{2}{|l|}{6 months } & \multicolumn{2}{|c|}{12 months } & \multicolumn{2}{|l|}{6 months } & \multicolumn{2}{|c|}{12 months } \\
\hline & $\begin{array}{l}\text { Number } \\
\text { of eyes }\end{array}$ & $\begin{array}{l}\% \text { of } \\
\text { eyes }\end{array}$ & $\begin{array}{l}\text { Number } \\
\text { of eyes }\end{array}$ & $\begin{array}{l}\% \text { of } \\
\text { eyes }\end{array}$ & $\begin{array}{l}\text { Number } \\
\text { of eyes }\end{array}$ & $\begin{array}{l}\% \text { of } \\
\text { eyes }\end{array}$ & $\begin{array}{l}\text { Number } \\
\text { of eyes }\end{array}$ & $\begin{array}{l}\% \text { of } \\
\text { eyes }\end{array}$ & $\begin{array}{l}\text { Number } \\
\text { of eyes }\end{array}$ & $\begin{array}{l}\% \text { of } \\
\text { eyes }\end{array}$ & $\begin{array}{l}\text { Number } \\
\text { of eyes }\end{array}$ & $\begin{array}{l}\% \text { of } \\
\text { eyes }\end{array}$ \\
\hline NLP & 55 & 28.5 & 48 & 34.0 & 30 & 22.9 & 25 & 27.2 & 25 & 40.3 & 23 & 46.9 \\
\hline LP/HM & 26 & 13.5 & 10 & 7.1 & 14 & 10.7 & 8 & 8.7 & 12 & 19.4 & 2 & 4.1 \\
\hline $1 / 200-19 / 200$ & 22 & II.4 & 14 & 9.9 & 18 & 13.7 & 8 & 8.7 & 4 & 6.5 & 6 & 12.2 \\
\hline $20 / 200-20 / 50$ & 42 & 21.8 & 39 & 27.7 & 31 & 23.7 & 28 & 30.4 & II & 17.7 & II & 22.4 \\
\hline$\geq 20 / 40$ & 48 & 24.9 & 30 & 21.3 & 38 & 29.0 & 23 & 25.0 & 10 & 16.1 & 7 & 14.3 \\
\hline Total & 193 & & $|4|$ & & 131 & & 92 & & 62 & & 49 & \\
\hline
\end{tabular}

Abbreviations: VR, vitreoretinal; NLP, no light perception; LP, light perception; HM, hand motion. 
Table 6 Comparison of patients initially treated by a vitreoretinal surgeon versus a non-vitreoretinal surgeon as stratified by initial zone of injury

\begin{tabular}{|c|c|c|c|c|}
\hline \multirow[t]{2}{*}{ Zone of injury } & \multicolumn{2}{|c|}{ Increase by one OTS category visual acuity } & \multicolumn{2}{|c|}{ Number of post-repair surgeries } \\
\hline & Odds ratio ${ }^{a}$ & $P$-value & Odds ratio $^{a}$ & $P$-value \\
\hline Zone I & 5.31 & 0.004 & 1.32 & 0.585 \\
\hline Zone II & 3.30 & 0.016 & 3.21 & 0.048 \\
\hline Zone III & 1.50 & 0.515 & $\mathrm{I} .44$ & 0.482 \\
\hline
\end{tabular}

Notes: adds ratios shown are the likelihood of increasing by one OTS visual acuity category and the likelihood of having at least one more follow-up surgery after initial globe repair. Data in bold indicates statistical significance.

Abbreviation: OTS, Ocular Trauma Score.

additional procedures on initial repair, patients treated by a VR surgeon were also 1.9 times more likely to have at least one follow-up surgery within the first year. As no significant differences exist between the type and zone of injury between the two groups of patients to explain the relatively greater number of follow-up surgeries, we believe that this may reflect a referral bias, perhaps due to recognition of the need for further posterior segment surgery at the time of initial repair, as the most common follow-up procedure was PPV. This pattern may also reflect a more aggressive mindset for surgical rehabilitation if initially treated by a VR surgeon, or suggest that the ability to perform VR-specific procedures necessary for surgical rehabilitation may influence a VR surgeon's willingness to employ these procedures in his/her approach to rehabilitation after globe trauma.

While one may hypothesize that patients with more posterior injuries have better visual acuity outcomes when initially treated by a VR surgeon, the data in our study do not support this hypothesis. When controlling for initial zone of injury, there was no statistically significant difference in visual acuity outcomes for eyes with posterior injuries $(P=0.52$ for Zone III). These data reflect the overall poor prognosis for eyes with Zone III injury due to irreparable damage to structures such as the retina or optic nerve, regardless of the subspecialty training of the initial treating surgeon.

By contrast, patients with more anterior (Zones I and II) injuries treated by a VR surgeon were more likely to improve by one OTS visual acuity category compared to those treated by non-VR surgeons ( $P=0.004$ and 0.016 for Zones I and II, respectively). In our series, eyes with Zone II injuries received more surgical rehabilitation when initially treated by a VR surgeon versus non-VR surgeon $(P=0.048)$, while rates of follow-up surgery for Zone I and III patients were similar. Patients with anterior (Zones I and II) injuries, thus, likely represent the group with the best chance for improvement with aggressive surgical rehabilitation. For example, injuries in Zones I and II may result in hyphema, vitreous hemorrhage, or lens damage causing poor presenting visual acuity. However, in the absence of damage to posterior segment structures, significant improvements in visual acuity may be possible with $\mathrm{AC}$ washout, vitrectomy, lensectomy, and intraocular lens implantation as part of surgical rehabilitation.

When comparing the rates of follow-up surgeries in patients initially treated by a VR versus non-VR surgeon, only the rates of $\mathrm{AC}$ washouts and SBs were different to a statistically significant degree. There was no statistically significant difference in the rate of secondary enucleations in the VR versus non-VR groups. When comparing the rate of primary enucleations between the VR and non-VR groups, however, the difference was significant $(P=0.01)$. Out of the 191 eyes that had at least 6 months of follow-up, 12 eyes had primary enucleation performed. Nine of these cases were initially staffed by a non-VR surgeon ( $15 \%$ of the patients in the non-VR group vs $6 \%$ in the VR group). This in combination with the greater number of follow-up procedures within the VR group may suggest that VR surgeons, with knowledge and ability to perform VR-specific procedures at time of initial repair or on follow-up, may opt for initial attempt at surgical repair and subsequent rehabilitation despite poor presenting visual acuity.

While our study provides evidence that procedures performed by VR surgeons may improve patient outcome following traumatic globe injuries, limitations of the study include its retrospective nature and relatively small number of eyes. The results may not be generalized to younger patients with globe trauma, as only adult patients were included in the study due to difficulty in assessing visual acuity for calculation of OTSs in a pediatric population. Approximately a third of the patients in this study did not have follow-up data at our institution past 6 months, in most cases because the patients were referred at time of trauma for initial repair and had follow-up care performed locally. Despite the lack of follow-up data, the presenting characteristics of eyes lost to follow-up were similar to those included in our study. Our study was not powered to compare outcomes across each individual subspecialty, but only compares outcomes between surgeons with VR training versus those without. The study was also not sufficiently powered to analyze the influence of surgeon experience on outcomes. 
Overall, our data suggest that nearly half of patients who suffer traumatic globe injuries undergo follow-up surgical rehabilitation within the first year. Eyes that were initially repaired by a VR surgeon had better visual outcomes than those treated by a non-VR surgeon. However, these eyes also underwent more surgical rehabilitation within the first year, and the difference was only apparent in anterior (Zones I and II) injuries. Notably, while there was a trend toward improved visual outcomes for Zone III injuries, there was no statistically significant difference between VR and non-VR groups, confirming the generally poor prognosis of these eyes and suggesting that posterior injuries may not mandate involvement of a VR surgeon versus a non-VR surgeon at time of initial repair. Eyes initially treated by a non-VR surgeon were more likely to undergo primary enucleation, and this may contribute to the difference in final visual acuity outcomes between the two groups.

Taken as a whole, these findings suggest that patients with anterior (Zones I and II) but not necessarily posterior (Zone III) traumatic globe injuries may have superior visual outcomes if initially treated by a VR surgeon, perhaps related to the use of VR-specific procedures at the time of initial repair and on follow-up surgeries for optimal rehabilitation in anterior injuries where visual prognosis is better. Future studies are needed to isolate factors that indicate when initial repair by a VR surgeon may be most beneficial. In circumstances where a VR surgeon is not immediately available for initial repair, early referrals to a VR surgeon should be considered following repair.

\section{Author contributions}

ICH, SP, and SS contributed to study design, data interpretation, and manuscript preparation and review. ICH and SP were involved in data collection and management. JW was involved with statistical analysis. All authors contributed toward data analysis, drafting, and revising the paper and agree to be accountable for all aspects of the work.

\section{Disclosure}

The authors report no conflicts of interest in this work.

\section{References}

1. Smith AR, O'Hagan SB, Gole GA. Epidemiology of open- and closedglobe trauma presenting to cairns base hospital, Queensland. Clin Experiment Ophthalmol. 2006;34(3):252-259.

2. Larque-Daza AB, Peralta-Calvo J, Lopez-Andrade J. Epidemiology of open-globe trauma in the Southeast of Spain. Eur J Ophthalmol. 2010; 20(3):578-583.

3. Schrader WF. Epidemiology of open globe eye injuries: analysis of 1,026 cases in 18 years. Klin Monbl Augenheilkd. 2004;221(8):629-635.

4. Dunn ES, Jaeger EA, Jeffers JB, Freitag SK. The epidemiology of ruptured globes. Ann Ophthalmol. 1992;24(11):405-410.

5. Negrel AD, Thylefors B. The global impact of eye injuries. Ophthalmic Epidemiol. 1998;5(3):143-169.

6. Kuhn F, Morris R, Witherspoon CD, Heimann K, Jeffers JB, Treister G. A standardized classification of ocular trauma. Ophthalmology. 1996; 103(2):240-243

7. Kuhn F, Morris R, Witherspoon CD. Birmingham eye trauma terminology (BETT): terminology and classification of mechanical eye injuries. Ophthalmol Clin North Am. 2002;15(2):139,43,v.

8. Pieramici DJ, Sternberg P Jr, Aaberg TM Sr, et al. A system for classifying mechanical injuries of the eye (globe). The ocular trauma classification group. Am J Ophthalmol. 1997;123(6):820-831.

9. Pieramici DJ, Au Eong KG, Sternberg P Jr, Marsh MJ. The prognostic significance of a system for classifying mechanical injuries of the eye (globe) in open-globe injuries. J Trauma. 2003;54(4):750-754.

10. Kuhn F, Maisiak R, Mann L, Mester V, Morris R, Witherspoon CD. The ocular trauma score (OTS). Ophthalmol Clin North Am. 2002;15(2): $163,5, \mathrm{vi}$

11. Unver YB, Kapran Z, Acar N, Altan T. Ocular trauma score in openglobe injuries. J Trauma. 2009;66(4):1030-1032.

12. Man CY, Steel D. Visual outcome after open globe injury: a comparison of two prognostic models - the ocular trauma score and the classification and regression tree. Eye (Lond). 2010;24(1):84-89.

13. Unal MH, Aydin A, Sonmez M, Ayata A, Ersanli D. Validation of the ocular trauma score for intraocular foreign bodies in deadly weaponrelated open-globe injuries. Ophthalmic Surg Lasers Imaging. 2008; 39(2):121-124.

14. Sobaci G, Akin T, Erdem U, Uysal Y, Karagül S. Ocular trauma score in deadly weapon-related open-globe injuries. Am J Ophthalmol. 2006; 141(4):760-761.

15. Unver YB, Acar N, Kapran Z, Altan T. Visual predictive value of the ocular trauma score in children. Br J Ophthalmol. 2008;92(8):1122-1124.

16. Andreoli MT, Andreoli CM. Surgical rehabilitation of the open globe injury patient. Am J Ophthalmol. 2012;153(5):856-860.

17. Cherry PM. Rupture of the globe. Arch Ophthalmol. 1972;88(5): 498-507.

18. De Juan E Jr, Sternberg P Jr, Michels RG. Penetrating ocular injuries. Types of injuries and visual results. Ophthalmology. 1983;90(11): $1318-1322$.

19. Schmidt GW, Broman AT, Hindman HB, Grant MP. Vision survival after open globe injury predicted by classification and regression tree analysis. Ophthalmology. 2008;115(1):202-209.

20. Pieramici DJ, MacCumber MW, Humayun MU, Marsh MJ, de Juan E Jr. Open-globe injury. Update on types of injuries and visual results. Ophthalmology. 1996;103(11):1798-1803.
Clinical Ophthalmology

\section{Publish your work in this journal}

Clinical Ophthalmology is an international, peer-reviewed journal covering all subspecialties within ophthalmology. Key topics include: Optometry; Visual science; Pharmacology and drug therapy in eye diseases; Basic Sciences; Primary and Secondary eye care; Patient Safety and Quality of Care Improvements. This journal is indexed on Submit your manuscript here: http://www.dovepress.com/clinical-ophthalmology-journal

\section{Dovepress}

PubMed Central and CAS, and is the official journal of The Society of Clinical Ophthalmology (SCO). The manuscript management system is completely online and includes a very quick and fair peer-review system, which is all easy to use. Visit http://www.dovepress.com/ testimonials.php to read real quotes from published authors. 